\title{
Localization (and profiles) of tyrosine- phosphorylated proteins in female reproductive organs of adult rats
}

\author{
Sudtida Bunsueb ${ }^{1}$, Nareelak Tangsrisakda ${ }^{1,2}$, Alexander T.H. Wu ${ }^{3,4}$, Sitthichai lamsaard ${ }^{1,2}$ \\ 'Department of Anatomy, Faculty of Medicine, Khon Kaen University, Khon Kaen; ${ }^{2}$ Research Institute for Human High Performance and Health \\ Promotion (HHP \& HP), Khon Kaen University, Khon Kaen, Thailand; ${ }^{3} \mathrm{PhD}$ Program for Translational Medicine, College of Medical Science and \\ Technology, Taipei Medical University and Academia Sinica, Taipei; ${ }^{4}$ Graduate Institute of Medical Sciences, National Defense Medical Center, Taipei, \\ Taiwan
}

Objective: Tyrosine phosphorylation is an essential process in many biological systems, including the male reproductive system. The presence of tyrosine-phosphorylated (TyrPho) proteins has been well documented in male reproductive organs, but research in fertile females is still limited.

Methods: The ovary, oviduct, and uterus of adult female Sprague-Dawley rats in the estrus phase were used to localize TyrPho proteins using an immunohistochemical technique. These proteins were separated and their expression patterns were examined by sodium dodecyl sulfatepolyacrylamide gel electrophoresis and Western blot analysis, respectively.

Results: TyrPho proteins were localized in the cytoplasm of the oocyte except the antral fluid; in the granulosa cells, theca cells, and stromal cells of the ovary; at the apical surface of oviductal epithelial cells; and in the basal epithelium and submucosa of the uterine wall. Moreover, we found that 72-, 43-, and 28-kDa TyrPho proteins were localized in the ovary, while 170-, 55-, and 43-kDa proteins were localized in the oviduct. In the uterus, we detected four major bands, corresponding to 61-, 55-, 54-, and 43-kDa TyrPho proteins.

Conclusion: Given that these TyrPho proteins were found in major reproductive organs in the estrus phase, these proteins may play important roles in female fertility.

Keywords: Ovary; Oviduct, Phosphorylation; Rats; Uterus

\section{Introduction}

Tyrosine phosphorylation is a post-transcriptional process that is essential to the regulation of cell proliferation, division, growth, and

Received: February 5, 2020 · Revised: March 13, 2020 · Accepted: April 1, 2020 Corresponding author: Sitthichai lamsaard

Department of Anatomy, Faculty of Medicine, Khon Kaen University,

123 Mitrapap Road, Amphoe Muang Khon Kaen 40002, Thailand

Tel: +66-4336-3212 Fax:+66-4336-3212 E-mail: sittia@kku.ac.th

This is an Open Access article distributed under the terms of the Creative Commons Attribution Non-Commercial License (http://creativecommons.org/licenses/by-nc/4.0/) which permits unrestricted non-commercial use, distribution, and reproduction in any medium, provided the original work is properly cited. differentiation [1-4]. In the male reproductive system, tyrosine-phosphorylated (TyrPho) proteins have been found to be localized in the Sertoli cells $[5,6]$, spermatogonia, spermatocytes, and Leydig cells, as well as the spermatids of rat testes [6], the epididymis epithelium [7], and the seminal epithelium and fluid [8]. Previous reports have demonstrated that the patterns of expression of testicular TyrPho proteins can be altered by drugs or other chemical agents [9-15]. Recently, Tongpan et al. [8] showed that TyrPho proteins were localized in the seminal epithelium and present in the seminal fluid and blood plasma. Moreover, it was recently demonstrated that the expression of a TyrPho protein was altered in the seminal vesicles of diabetic mice [16]. 
In the female system, TyrPho proteins were found to be localized in the pig oocyte and were assumed to be involved in the formation of chromatin during metaphase [17]. Richards et al. [18] also demonstrated the localization of TyrPho proteins in the uterine protein lysate of ovariectomized mice, an endogenous estrogen-deficient model. It has also been revealed that estrogen affects the tyrosine phosphorylation protein profiles in the uterine cycles of the oviparous lizard Lampropholis guichenoti and the viviparous lizard Eulamprus tympanum [19]. Although tyrosine phosphorylation has been investigated in certain female reproductive organs of both mammals and non-mammalian animals, the specific localization patterns of TyrPho proteins have never been assessed in organs such as the ovary, oviduct, and uterus in adult female rats. To better understand the fundamentals of tyrosine phosphorylation in the female reproductive system, this study aimed to investigate the localization and expression of TyrPho proteins in the ovary, oviduct, and uterus of adult fertile rats.

\section{Methods}

\section{Animals}

Four adult female Sprague-Dawley rats (mass, 200-250 g) with natural estrus were selected from six animals without hormonal induction as confirmed by a vaginal smear. The rats were obtained from the animal unit of the Khon Kaen University Faculty of Medicine in Khon Kaen, Thailand. The animals were kept in plastic cages under conditions of a 12-hour light/dark cycle, temperature of $23^{\circ} \mathrm{C} \pm 2^{\circ} \mathrm{C}$, relative humidity of $30 \%-60 \%$, sound level of $<85$ decibels, and light intensity of 350-400 lux in the Laboratory Animal Unit of the Khon Kaen University Faculty of Medicine. The animals received commercial pellet food and water ad libitum. This study was approved by the Animal Research Ethics Committee of the Khon Kaen University Faculty of Medicine (No. AEMDKKU 011/2019), in accordance with the Ethical Principles and Guidelines for the Use of Animals for Scientific Purposes published by the National Research Council of Thailand.

\section{Immunohistochemical analysis}

After euthanasia, the ovary, oviduct, and uterus of each animal were routinely processed into paraffin blocks. Then, the paraffinized female reproductive tissue sections were placed on gelatin-coated glass slides and dried in a hot air oven $\left(60^{\circ} \mathrm{C}\right)$. All tissue sections were deparaffinized with xylene and rehydrated before antigen retrieval by soaking in citrate buffer ( $\mathrm{pH} 6.0$ ) and heating using a microwave at $80^{\circ} \mathrm{C}-95^{\circ} \mathrm{C}$ for 2 minutes. Then, the antigen-retrieved slides were cooled and washed with phosphate-buffered saline (PBS). Endogenous peroxidase activity was blocked with $30 \% \mathrm{H}_{2} \mathrm{O}_{2}$ in PBS for 30 minutes, after which the blocking of nonspecific proteins was in- duced by incubation with $0.3 \%$ bovine serum albumin (MilliporeSigma, Burlington, MA, USA) in PBS in a moist chamber overnight. The sections of tissue were further incubated with mouse phosphotyrosine monoclonal antibody (MilliporeSigma) diluted in PBS (1:200 [v/ v]) at $4^{\circ} \mathrm{C}$ overnight, whereas the negative control slides were not treated with this primary antibody. After washing with PBS for 5 minutes to remove the excess antibody, all sections were incubated with horseradish peroxidase-conjugated goat anti-mouse immunoglobulin G (dilution 1:300 [v/v]; Invitrogen, Carlsbad, CA, USA) at $25^{\circ} \mathrm{C}$ for 2 hours. Subsequently, the sections were incubated with the $3,3^{\prime}$-diaminobenzidine (DAB) substrate (Vector Laboratories, Burlingame, (A, USA) and counterstained with hematoxylin for 5 minutes. Then, all sections were dehydrated and cleared with xylene before mounting with dibutyl phthalate polystyrene xylene (BDH Laboratories, Poole, UK). Images of positive immunoreactivity of the tissue sections were captured using a Nikon Light ECLIPSE E200 light microscope equipped with a DXM1200 digital camera (Nikon, Tokyo, Japan).

\section{Western blot analysis}

To investigate the levels of localization of TyrPho proteins in the ovary, oviduct, and uterus, the total proteins of each tissue lysate were loaded at $100 \mu \mathrm{g} /$ lane and separated via $10 \%$ sodium dodecyl sulfate -polyacrylamide gel electrophoresis (SDS-PAGE). Then, the separated proteins on the SDS gel were transferred onto a nitrocellulose membrane. Subsequently, all transferred protein membranes were incubated with $5 \%$ skim milk in $0.1 \%$ TBST $(0.1 \%$ Tween-20 with tris-buffered saline, $\mathrm{pH}$ 7.4) for 1 hour to block nonspecific protein binding. All membranes of the ovary, oviduct, and uterus protein lysates were incubated with primary anti-phosphotyrosine antibody (1:2,000 dilution, catalog no. $05-321$; MilliporeSigma) at $4^{\circ} \mathrm{C}$ overnight followed by washing and incubating with secondary antimouse antibody (1:2,000 dilution, TM catalog number G-21234; Invitrogen) in $0.1 \%$ TBST for 1 hour at room temperature. Epidermal growth factor (MilliporeSigma) was used as a positive control with regard to tyrosine phosphorylation, while bovine serum albumin (MilliporeSigma) was used as a negative control. An enhanced chemiluminescence substrate reagent kit (GE Healthcare Life Sciences, Chicago, IL, USA) was used for incubation prior to visualization under gel documentation protocol 4 (ImageQuant 400; GE Healthcare Life Sciences) at the Vejawichakarn building of the Khon Kaen University Faculty of Medicine. For quantitative analysis, the relative intensity of protein expression was measured and analyzed using the ImageJ software program version 1.49 (National Institutes of Health, Bethesda, MD, USA). 


\section{Results}

The immunolocalization of TyrPho proteins in female reproductive organs during the estrus phase is shown in Figure 1. Compared to the negative control (Figure 1D-F), the results revealed that TyrPho proteins were localized in the stroma of the ovary and in all developing ovarian follicles, especially mature follicles (Figure 1A). TyrPho proteins were observed to be localized in the cytoplasm of the oocyte and in granulosa cells, theca cells, and stroma cells; however, these proteins were not detected in the antrum (Figure 1B). More- over, compared to the negative control, TyrPho proteins were found to be localized at the apical surface of oviductal epithelial cells (Figure 1) as well as in the basal cytoplasm and submucosa of the uterine tube epithelium (Figure 1C). The negative control was not treated with primary antibody and was counterstained with hematoxylin as shown in Figure 1D-F.

In addition, the levels of TyrPho proteins in the ovary, oviduct, and uterus are demonstrated in Figure 2. The protein profiles of each organ were revealed by SDS-PAGE with Coomassie blue staining (Figure 2). Figure $2 \mathrm{~A}$ shows that $72-, 43-$, and $28-\mathrm{kDa}$ TyrPho proteins
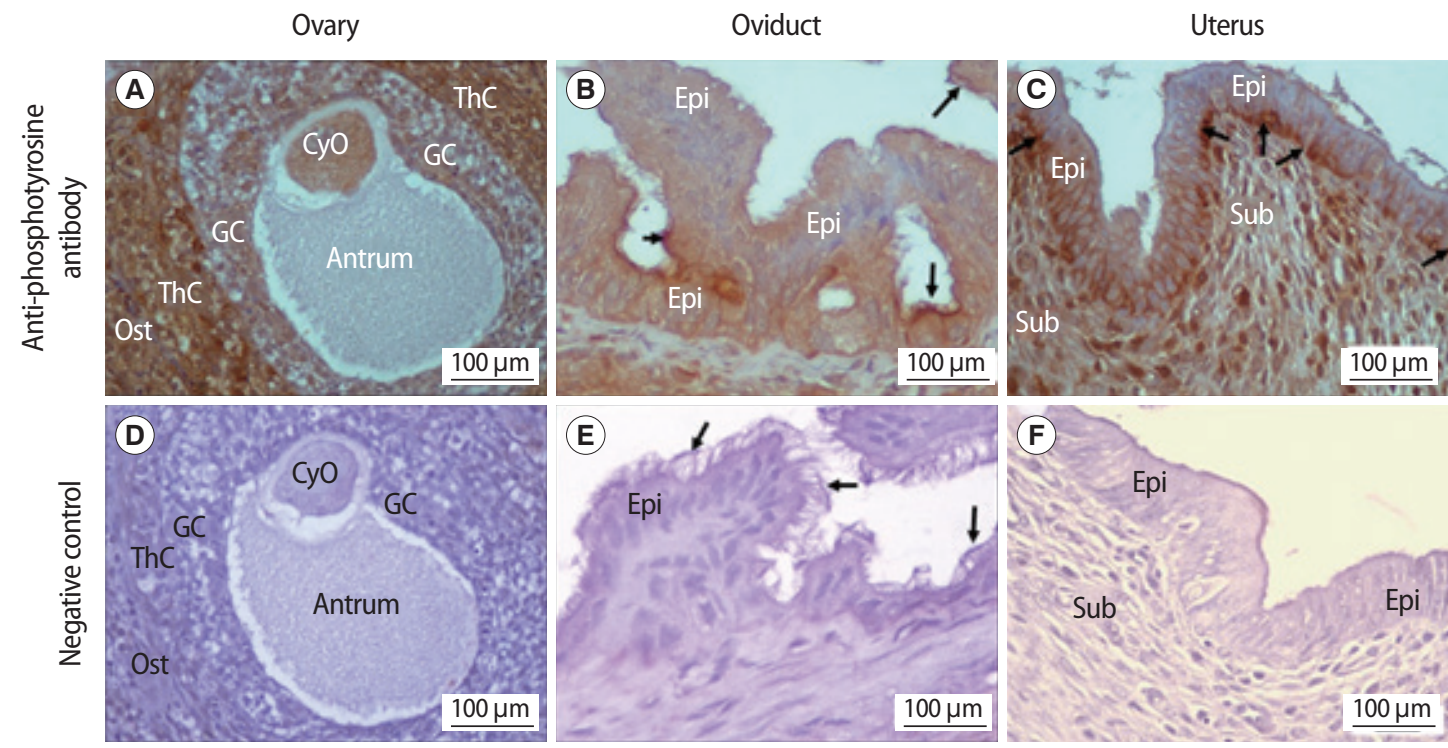

Figure 1. Immunohistochemical micrographs stained with 3,3'-diaminobenzidine (DAB) demonstrating the localization of anti-phosphotyrosine antibody in the female reproductive organs (the mature follicles of the ovary, oviduct, and uterus; A-C). The negative control (D-F) was not treated with primary antibody. CyO, cytoplasm of the oocyte; GC, granulosa cell; ThC, theca cell; Ost, ovarian stroma cell; Epi, epithelial cell; Sub, submucosa.
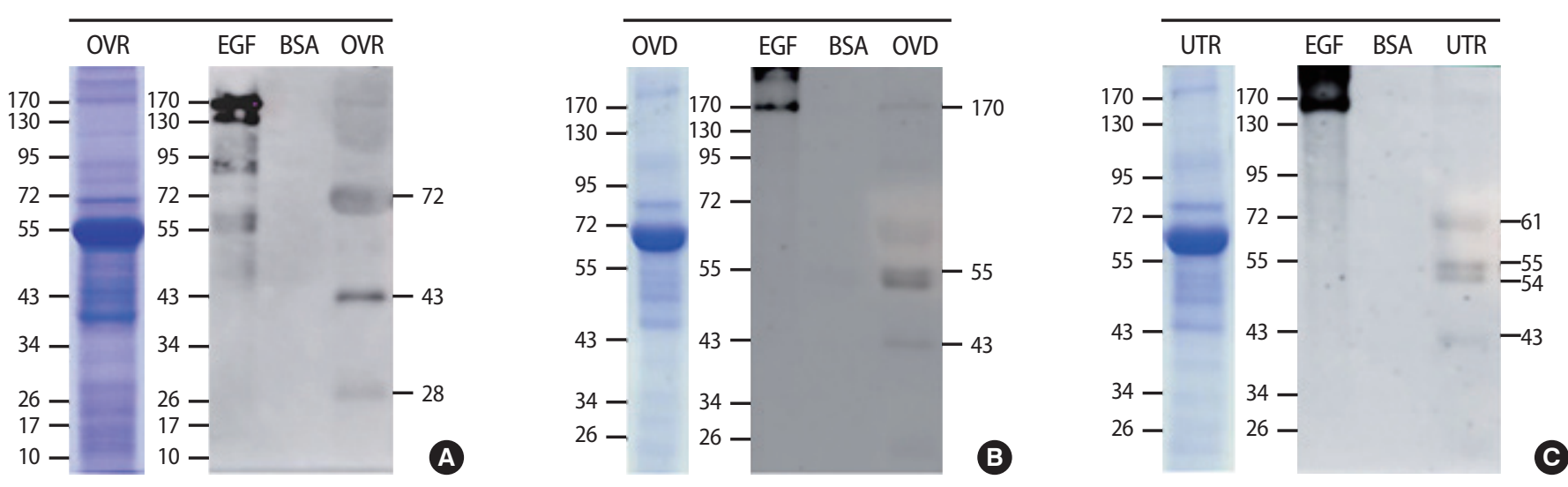

Figure 2. Protein profiles (100 mg/lane) of the ovary (OVR; A), oviduct (OVD; B), and uterus (UTR; C). Proteins were separated by sodium dodecyl sulfate-polyacrylamide gel electrophoresis with Coomassie blue staining and Western blotting with anti-phosphotyrosine antibody. EGF, epidermal growth factor (used as a positive control for tyrosine phosphorylation); BSA, bovine serum albumin (used as a negative control). 


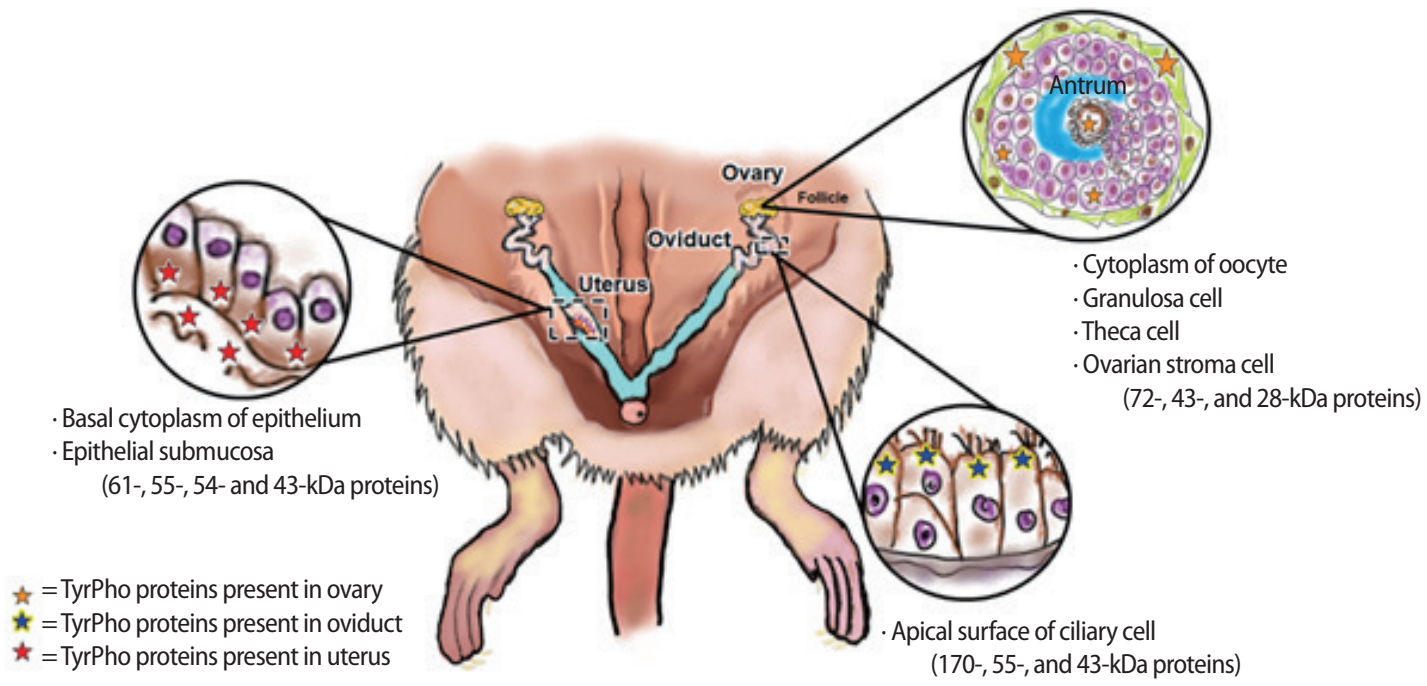

Figure 3. Summary of the localization of tyrosine-phosphorylated (TyrPho) proteins in the ovary, especially in the mature follicle (72-, 43-, and 28-kDa proteins), oviduct (170-, 55-, and 43-kDa proteins), and uterus (61-, 55-, 54-, and 43-kDa proteins), of adult female rats in the estrus phase.

were localized in the adult rat ovary. In the oviduct, 170-, 55-, and 43$\mathrm{kDa}$ TyrPho proteins were clearly localized (Figure 2B). Moreover, in the total protein lysate of the uterus, four major bands were observed, corresponding to the expression of 61-, 55-, 54-, and 43-kDa TyrPho proteins (Figure 2C).

\section{Discussion}

Tyrosine phosphorylation is known to play important roles in the internal fertilization processes of mammals, especially in capacitation and the acrosome reaction. Additionally, TyrPho proteins have been shown to be localized in the testis [9-15], epididymis [7], and seminal vesicle [8] by using anti-TyrPho antibodies (clone 4G10; catalog no. 05-321; MilliporeSigma). Such localization patterns indicate the importance of TyrPho proteins in the facilitation of primary male fertility via roles in spermatogenesis, androgen production, functional sperm maturation, and seminal fluid production. Regarding the female system, the localization patterns of TyrPho proteins are summarized in Figure 3. Previously, a 42-kDa TyrPho protein was found in the cytoplasm of ovulated secondary oocytes in pigs [17]; however, the present study was the first to demonstrate the presence of multiple TyrPho proteins in adult rat ovarian tissue (Figure 3). Miyano et al. [17] suggested that the 42-kDa TyrPho protein detected in the pig oocyte may be involved in the formation of chromatin during metaphase.

Many studies have reported that TyrPho proteins in capacitated sperm induced in the female reproductive tracts, particularly the oviduct, are associated with male fertility [20-22]. However, the expression and localization patterns of TyrPho proteins in the rat oviduct have never been reported. Our study was the first to report the pres- ence of multiple TyrPho proteins in the apical epithelium of the oviduct (Figure 1). Moreover, the oviductal TyrPho proteins detected in this study had masses of 170, 55, and $43 \mathrm{kDa}$, as summarized in Figure 3. These oviductal TyrPho proteins may play roles in sperm capacitation and the acrosome reaction when sperm travel into the oviduct to fertilize the ovulated egg. In an ovariectomized mouse model, Richards et al. [18] revealed that TyrPho proteins are also localized in the uterus; specifically, they identified the presence of 180and $170-\mathrm{kDa}$ TyrPho proteins in uterine epithelial cells. Their results suggested that the expression of those TyrPho proteins is regulated by estrogen [18]. In addition, 61-, 52-, and 48-kDa TyrPho proteins have been demonstrated to be localized in the uterus of the oviparous lizard L. guichenoti and the viviparous lizard E. tympanum [19]. As demonstrated by Richards et al. [18] in the mouse uterus, in the present study, we found a $170-\mathrm{kDa}$ TyrPho protein in rat uterine tissue (Figure 2). Moreover, this study showed that additional TyrPho proteins (with masses of 70,55 , and $43 \mathrm{kDa}$ ) are localized in the adult rat uterus and localized in the epithelial cells and the submucosa and basal cytoplasm of the epithelium (Figures 2 and 3). In contrast, the expression patterns of uterine TyrPho proteins demonstrated in the present study are entirely different from those previously observed in vertebrate lizards [19]. These findings suggest that a 170-kDa protein may be conserved for some uterine functions in mammalian animals, especially the mouse and rat, while lower vertebrates may use different TyrPho proteins to maintain their uterine physiology. To discover and better understand the functions of TyrPho proteins found in the ovary, oviduct, and uterus in our study, these proteins must be identified and further characterized using proteomics.

In this study, we report that TyrPho proteins are localized in the 
ovary, oviduct, and uterus of adult female rats in the estrus phase. Those proteins can be separated and clearly detected in the tissue lysate, indicating that TyrPho proteins may play important roles in female fertility.

\section{Conflict of interest}

No potential conflict of interest relevant to this article was reported.

\section{Acknowledgments}

We would like to thank the Khon Kaen University Faculty of Medicine for kindly providing financial support via an Invitation Research Grant (IN 62336) to Miss Sudtida Bunsueb and Associate Professor Dr. Sitthichai lamsaard.

\section{ORCID}

Sudtida Bunsueb

Nareelak Tangsrisakda

AlexanderT.H.Wu

Sitthichai lamsaard https://orcid.org/0000-0001-9067-1403 https://orcid.org/0000-0003-2444-8478 https://orcid.org/0000-0002-0178-6530 https://orcid.org/0000-0002-6793-2879

\section{Author contributions}

Conceptualization: SI, ATHW. Data curation: SB. Formal analysis: SB, NT. Funding acquisition: SI. Methodology: SB, NT. Project administration: SI. Visualization: NT, SI. Writing-original draft: SI, SB. Writing-review \& editing: SI, ATHW.

\section{References}

1. Keller N, Ozmadenci D, Ichim G, Stupack D. Caspase-8 function, and phosphorylation, in cell migration. Semin Cell Dev Biol 2018;82:105-17.

2. Grindheim AK, Saraste J, Vedeler A. Protein phosphorylation and its role in the regulation of Annexin A2 function. Biochim Biophys Acta Gen Subj 2017;1861(11 Pt A):2515-29.

3. Hanks SK, Quinn AM, Hunter T. The protein kinase family: conserved features and deduced phylogeny of the catalytic domains. Science 1988;241:42-52.

4. Ullrich $A$, Schlessinger J. Signal transduction by receptors with tyrosine kinase activity. Cell 1990;61:203-12.

5. Arad-Dann H, Beller U, Haimovitch R, Gavrieli Y, Ben-Sasson SA. Immunohistochemistry of phosphotyrosine residues: identification of distinct intracellular patterns in epithelial and steroidogenic tissues. J Histochem Cytochem 1993;41:513-9.
6. Chaichun A, Arun S, Burawat J, Kanla P, lamsaard S. Localization and identification of tyrosine phosphorylated proteins in adult Sprague-Dawley rat testis. Int J Morphol 2017;35:1322-7.

7. Sawatpanich T, Arun S, Tongpan S, Chaichun A, Sampannang A, Sukhorum $W$, et al. Localization and changes of tyrosine phosphorylated proteins and $B$ actin in epididymis of rats treated with valproic acid. Int J Morphol 2018;36:835-40.

8. Tongpan S, Sukhorum W, Arun S, Sawatphanich T, lamsaard S. Valproic acid changes the expression of tyrosine-phosphorylated proteins in rat seminal vesicle. Andrologia 2019;51:e13303.

9. lamsaard S, Burawat J, Kanla P, Arun S, Sukhorum W, Sripanidkulchai $B$, et al. Antioxidant activity and protective effect of Clitoria ternatea flower extract on testicular damage induced by ketoconazole in rats. J Zhejiang Univ Sci B 2014;15:548-55.

10. lamsaard $S$, Burawat J, Arun $S$, Sukhorum W, Boonruangsrim $P_{1}$ Namking M, et al. Phyllanthus emblica L. Branch extract ameliorates testicular damage in valproic acid-induced rats. Int J Morphol 2015;33:1016-22.

11. Sampannang A, Arun S, Sukhorum W, Burawat J, Nualkaew S, Maneenin C, et al. Antioxidant and hypoglycemic effects of Momordica cochinchinensis spreng: (Gac) aril extract on reproductive damages in Streptozotocin (STZ)-induced hyperglycemia mice. Int J Morphol 2017;35:667-75.

12. Sampannang A, Arun S, Burawat J, Sukhorum W, lamsaard S. Expression of testicular phosphorylated proteins in types 1 and 2 diabetes mellitus in mice: an experimental study. Int J Reprod Biomed (Yazd) 2019;17:567-76.

13. Sukhorum W, lamsaard S. Changes in testicular function proteins and sperm acrosome status in rats treated with valproic acid. Reprod Fertil Dev 2017;29:1585-92.

14. Maneenin C, Burawat J, Maneenin N, Nualkaew S, Arun S, Sampannang A, et al. Antioxidant capacity of Momordica charantia extract and its protective effect on testicular damage in valproic acid-induced rats. Int J Morphol 2018;36:447-53.

15. Arun S, Burawat J, Yannasithinon S, Sukhorum W, Limpongsa A, lamsaard S. Phyllanthus emblica leaf extract ameliorates testicular damage in rats with chronic stress. J Zhejiang Univ Sci B 2018; 19:948-59.

16. Yannasithinon S, lamsaard S. Alterations of morphology and phosphorylated protein expression in the seminal vesicles of diabetic mice. Andrologia 2019;51:e13406.

17. Miyano T, Moor RM, Wooding FB, Shiroo M. Localization and function of tyrosine-phosphorylated protein in pig oocytes. Mol Reprod Dev 1996;44:408-16.

18. Richards RG, Di Augustine RP, Petrusz P, Clark GC, Sebastian J. Estradiol stimulates tyrosine phosphorylation of the insulin-like growth factor-1 receptor and insulin receptor substrate-1 in the 
uterus. Proc Natl Acad Sci USA 1996;93:12002-7.

19. Thomson M, Herbert JF, Thompson MB. Tyrosine phosphorylated proteins in the reproductive tract of the viviparous lizard Eulamprus tympanum and the oviparous lizard Lampropholis guichenoti. Comp Biochem Physiol B Biochem Mol Biol 2006;144:382-6.

20. Yeung CH, Wagenfeld A, Nieschlag E, Cooper TG. The cause of infertility of male c-ros tyrosine kinase receptor knockout mice.
Biol Reprod 2000;63:612-8.

21. Naz RK, Rajesh PB. Role of tyrosine phosphorylation in sperm capacitation / acrosome reaction. Reprod Biol Endocrinol 2004;2:75.

22. Kumaresan A, Johannisson A, Bergqvist AS. Sperm function during incubation with oestrus oviductal fluid differs in bulls with different fertility. Reprod Fertil Dev 2017;29:1096-106. 